\title{
Budget deficits and inflation feedback ${ }^{1}$
}

\author{
Sergey Pekarski \\ Centre for Advanced Studies \\ State University - Higher School of Economics, Moscow
}

August, 2007

\begin{abstract}
This paper contributes to the literature on budget deficits and inflation in high inflation economies. The main finding is that recurrent outbursts of extreme inflation in these economies can be explained by a certain hysteresis effect associated with public finance. This interpretation meets the evidence that dramatic shifts between regimes of moderately high and extremely high (hyper-) inflation often occur without visible deterioration in public finance or abrupt shifts in fiscal and monetary policies. The existence of the hysteresis effect is explicitly explained by the work of two mechanisms: the arithmetic associated with the wrong side of the inflation tax Laffer curve and the Patinkin effect (the reverse of the much more-cited Olivera-Tanzi effect). It is also shown that the division of the operational budget deficit into the part that is subject to negative inflation feedback and the inflation-proof part has implications for both the discussion of inflationary consequences of budget deficits and the proper design of stabilization policy.
\end{abstract}

JEL Classification: E41, E52, E61, E63.

Keywords: budget deficit, high inflation, the Patinkin effect.

\footnotetext{
${ }^{1}$ This paper was prepared when S. Pekarski visited CORE, UCL.
} 
«...given that policymakers do not create inflation out of a clear blue sky, it is almost certain that countries with high inflation rates are countries that are already in trouble for fiscal or other reasons, and thus that it will be either impossible or extremely difficult to deal definitely with the issue of causation».

Fischer (1995, p.22)

\section{Introduction}

In most cases a high level of inflation can be explained by the nature of the interaction between fiscal and monetary policies. Indeed, for most episodes of high inflation in developing countries we can say that the source of inflation is an imbalance in the fiscal sphere. However, is the causality between inflation and the deficit actually so clear?

This question is obviously important. It is hard to not agree with Stanley Fischer's statement. Indeed, even though an imbalance in the fiscal sphere may be considered to be one of the major reasons for high inflation, statistical data often do not explicitly show a correlation between a decrease in the deficit and a fall in the inflation rate.

Several important stylized facts about fiscal policy and inflation dynamics in modern high inflation economies are in focus of this paper. We do not provide a complete list of these facts and we narrow the analysis to a pure fiscal-monetary framework, leaving out other important issues, such as inflation inertia, exchange rate dynamics, etc. Instead we concentrate on some of the evidence that is not fully compatible with standard monetary-fiscal models of inflation dynamics:

- $\quad$ Recurrence of extremely high inflation. While classical interwar hyperinflations appeared in previously stable financial systems and were stabilized almost immediately and almost at zero cost, modern extremely high and hyperinflations represent the outburst of inflation in chronically high inflation economies. In this case stabilization of hyperinflation (extreme inflation) almost everywhere means the recurrence to moderately high inflation.

- Inflation effects on budget deficit. In high inflation economies there is a significant feedback from inflation to real budget deficit. This feedback has various channels and in general it is unclear whether inflation acts as a "stabilizer" or a "destabilzer" of public finance.

- Inflation tax Laffer curve. Data on some high inflation episodes demonstrates the existence of the "Laffer curve effect": the inflation tax may be a decreasing function of inflation when the 
inflation rate is too high. At the same time, an outburst of hyperinflation is very often associated with roughly constant or even decreasing seigniorage revenue.

- Relationship between deficits and inflation. While on average an increase in the budget deficit in high inflation economies is associated with an increase in the rate of inflation, this relationship is not always strong and sometimes may even be of the opposite sign.

- Stability of money demand. Demand for real money balances is not a stable function of inflation during extreme inflation and hyperinflation episodes.

This paper provides a reconciliation between this evidence and the inflation tax Laffer curve model that takes into account the negative feedback from inflation to real budget deficit. In Section 2 we start with the explanation of why it is hard to explain all these stylized facts taken together within the basic model of the budget deficit's monetization. The next two sections give an analysis of the relationship between inflation and budget deficit under alternative assumptions about the form of inflation feedback. The final section contains a summary and discussion of the main results.

\section{Budget deficits and inflation: recent theory and evidence}

\section{Modern extreme inflations versus classical hyperinflations}

There are two types of hyperinflation processes known to economic history: "classical" interwar European hyperinflations (Germany, 1922-23; Austria, 1921-22; Hungary, 1923-24; among others) ${ }^{2}$ and more recent hyperinflations experienced by chronic high-inflation countries (Argentina, 198990; Brazil, 1989-90; Bolivia, 1984-85; Congo (Dem.Rep.) 1991-91, 1993-94; Nicaragua, 1986-91; Zimbabwe, 2006-2007; among others). All these episodes meet Cagan's definition of hyperinflation (monthly inflation rate that is over 50 percent for at least a year) and have rather similar characteristics of the dynamics of fiscal and monetary variables. However, they are different in one important aspect. In general, classical hyperinflations took place when a previously stable financial system was disrupted by extraordinary events (such as wars or economic transition), and after they were stabilized the economy returned to its normal functioning under relatively low and stable inflation. Modern hyperinflations take place in chronically high inflation countries. In most cases after the end of the hyperinflation period, economies reverted to high or moderate, but still very unstable inflation. This point can be stressed further, if one considers the more general framework of the switching between two regimes: "moderately high" and "extremely high" inflation that is the

\footnotetext{
${ }^{2}$ Hyperinflations following the transition to market economies in the early 1990's may be also attributed to the first type. The Serbian hyperinflation of 1993-94 is the most dramatic example.
} 
true story of such countries as Argentina and Brazil over the last few decades. The question that we address in this paper is what specific economic forces determine this switch between "moderately high" and "extremely high" inflation regimes in these countries? And why is this indeed an abrupt switch, and not a gradual slipping down?

\section{Inflation effects on budget deficit}

The standard explanation of the end of "classical" hyperinflation (at almost no cost and with the permanent shift to stable low inflation) involves the assumption of rational expectations and credibility of future policy switches. ${ }^{3}$ Obviously, this mechanism may not work in economies that live with moderate or high inflation for decades and it can not account for observed recurrent outbursts of hyperinflation. ${ }^{4}$ It is well known that these economies are prone to different market mechanisms (indexation schemes) that generate significant inflation inertia, making stabilization programs costly and difficult to implement. However, in a situation when market economy creates mechanisms that help it to live with high inflation (that actually acts like "stabilizers" or "traps") one should obviously expect the existence of certain "stabilizers" in highly unstable public finance. In this paper we explore the role of one of such "stabilizer", the so-called "Patinkin effect", that refers to the negative effects of inflation on the budget deficit. ${ }^{5}$ If this effect is present, it not only acts as a stabilizer of fiscal imbalance, but it also weakens the incentives for policy-makers to fight inflation. ${ }^{6}$ Indeed, decades of high inflation and numerous unsuccessful stabilization programs in some Latin American countries support this view. Obviously, there are many channels through which inflation exerts influence upon the real budget deficit. The most cited is the "Olivera-Tanzi effect" (Olivera, 1967; Tanzi, 1977) that deteriorates real budget revenues through tax's collection lags. This effect destabilizes public finance. It should thus strengthen the incentives to stabilize high inflation. While the Olivera-Tanzi effect was reported for several high inflation economies, the opposite Patinkin effect remains (to our knowledge) out of focus. However, as long as both effects are partial, one can not be sure what the overall effect is. This consideration demands a deeper empirical investigation. From the theoretical point of view, there are two major reasons why the dominance of the Patinkin effect is an appealing assumption. First, as we show in this paper,

\footnotetext{
${ }^{3}$ See the original explanation of this logic in Sargent (1982) and the more recent model by Barbosa, Cunha and Sallum (2006).

${ }^{4}$ There are only a few exceptions, such as Israel's credible stabilization in 1985-86.

5 The term "Patinkin effect" was suggested by Cardoso (1998). In exploring Israel's stabilization program of 1985 , Patinkin (1993) stressed the importance of the negative effect of inflation on government spending. Cardoso (1998) states that this effect was dominant in Brazil over the last few decades. We will return to the nature of this effect in the next section.

${ }^{6}$ Thus the Patinkin effect may be considered as an alternative explanation of delayed stabilization without explicit reference to political mechanisms (see, Drazen, 2000). Cardoso and Helwege (1999) stress that when inflation is reduced (or temporarily repressed), the disappearance of those factors that "stabilize" the budget deficit at high inflation throws down a challenge for the government to continue its stabilization efforts.
} 
adjusting the model to take the Olivera-Tanzi effect into account does not produce qualitatively new results, while the Patinkin effect does. Second. As we just noted, the assumption that public finance in high inflation economies has some internal stabilizers is appealing, because it helps to explain why high inflation may continue for decades.

\section{The inflation tax Laffer curve and multiple equilibria}

Various empirical investigations (Edwards and Tabellini, 1991; and more recently Bali and Thurston, 2000; and Fischer, Sahay and Vegh, 2002, among others) have found the so-called "Laffer curve effect": the inflation tax, which is used to finance public spending when the government is unable to raise a sufficient amount of conventional taxes or to borrow from the public or abroad, is a limited source of finance. It increases with an increase in inflation only until money demand is inelastic on the so-called "efficient side". When the inflation rate becomes significantly high, the economy begins to operate on the falling branch ("wrong side") of the inflation tax Laffer curve (ITLC).

The existence of the Laffer curve effect was challenged both on theoretical and empirical grounds for some historical episodes. Gutierrez and Vazquez (2004) show that ITLC arises in a cash-in-advance model only for an unrealistically high intertemporal substitution of consumption. The existence of ITLC in a money-in-the-utility function model also requires a specification of preferences that is similar to that studied by Calvo and Leiderman (1992). Eckstein and Leiderman (1992) and Bental and Eckstein (1997) stress the point that seigniorage revenue remained actually trendless despite a dramatic increase in inflation in Israel in 1979-1985. Kiguel and Neumeyer (1995) also indicate that Argentina remained on the "efficient" side of the Laffer curve in the tabelita and pre-Austral periods. Bali and Thurston (2000) provide an empirical estimation of the Laffer surface, explicitly taking into account the reserves ratio, the variation of which is important for inflation tax revenue. They report cases of high and even moderate inflation economies operating in the "wrong side". Some countries (Venezuela, Spain, Pakistan and UK among others) are very frequently on the wrong side but at rather moderate inflation, while some countries (Argentina and Bolivia among others) find themselves infrequently on the wrong side but at extremely high inflation.

If one agrees that the ITLC is plausible (at least in some cases) both on theoretical and empirical grounds, then there exist two levels of inflation ("low inflation" at the efficient side of the Laffer curve and "high inflation" on its wrong side) that can provide the same amount of inflation tax. This fact raises two general concerns. The first is the so-called "Cagan's Paradox": why does an economy fall into the wrong side of the ITLC if it is possible to collect the same amount of inflation tax at a lower (and thus Pareto efficient) rate of inflation? In the literature this problem is treated as 
a problem of dual equilibria, and thus one has to explain why the economy is "trapped" in a Paretoinefficient equilibrium. In this paper we show that if the Patinkin effect is in place, then there could be no low inflation equilibrium at the "efficient side" at all. Thus a steady state on the "wrong side" of the Laffer curve is not a paradox.

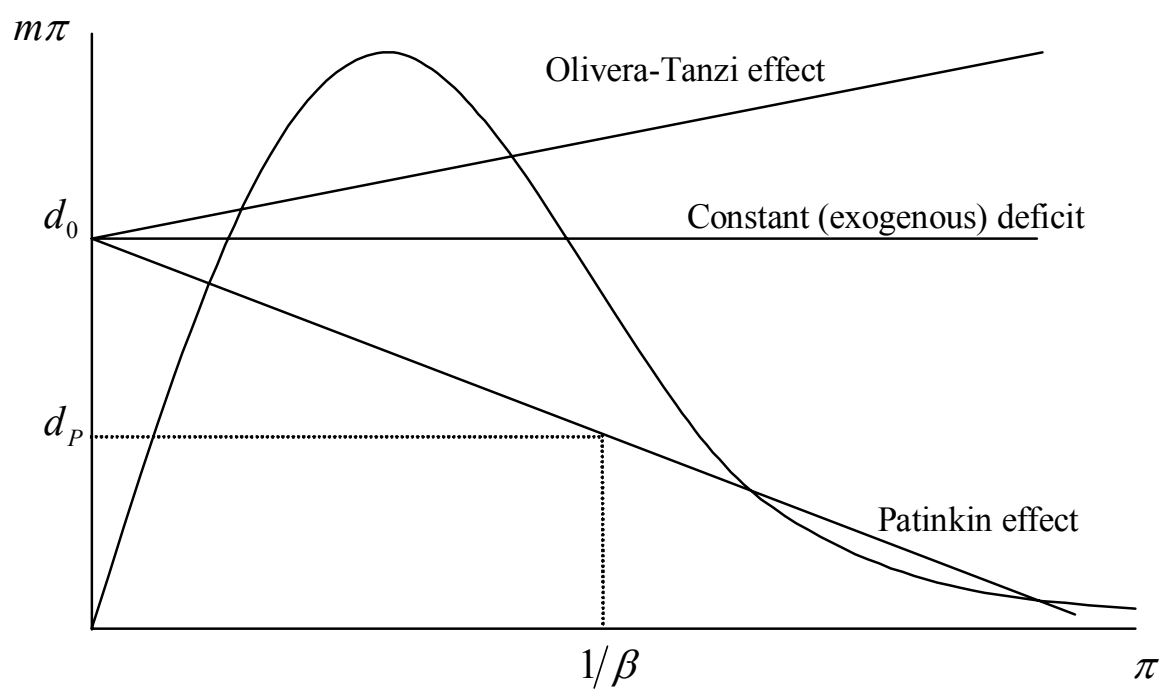

Fig. 1. Inflation tax Laffer curve

The second issue that is unavoidable in the context of dual (multiple) equilibria is the stability analysis. The standard model that can be used to analyze inflation dynamics induced by budget deficit finance can be represented by the following equation: ${ }^{7}$

$$
\frac{\dot{M}}{P}=D
$$

The operational budget deficit, $D$, that in general includes the primary budget deficit and debt service, is financed by seigniorage, $S .{ }^{8}$ By definition, seigniorage is the real revenue from money emission, $S=\dot{M} / P$, where $M$ is base money, and $P$ is price level. Seigniorage may be further decomposed into two components: the so-called pure seigniorage, $\dot{m}$ (the increase in real money balances, $m=M(P)$, and the inflation tax, $m \pi$, where $\pi=\dot{P} / P$ is the rate of inflation. Seigniorage can also be written as $\mu m$, the product of the growth rate of base money, $\mu=\dot{M} / M$, and real money balances. Taking these relationships together, we can write $S=\dot{M} / P=\dot{m}+m \pi=\mu m$. It is usually assumed that the money market is always in equilibrium and that the demand for real money balances can be described by a Cagan-type function that is a

\footnotetext{
${ }^{7}$ This model was developed and explored by Evans and Yarrow (1981), Sargent and Wallace (1987), Bruno and Fischer (1990), among others.

${ }^{8}$ All variables in the general case are functions of time, but this, however, is not shown in the text in order to simplify notation. A dot above a variable indicates a derivative with respect to time.
} 
monotonic decreasing function of the expected rate of inflation: $M^{S} / P=m^{D} \equiv m\left(\pi^{e}\right), m^{\prime}(\cdot)<0$. Furthermore, if the demand for real money balances has both elastic and inelastic parts, then, assuming that expected inflation rate is equal to actual inflation rate in the steady state, the inflation tax, $m \pi$, is a hump-shaped function of inflation represented in Fig. 1.

The next step is to assume some particular mechanism for forming expectations. The adaptive expectations hypothesis and the perfect foresight hypothesis have been most commonly used in the literature. The former mechanism is described by equation:

$$
\dot{\pi}^{e}=\theta\left(\pi-\pi^{e}\right)
$$

where $\theta>0$ stands for the speed of adaptation of expected inflation to its actual rate. Perfect foresight hypothesis is a special case of rational expectations hypothesis. It may be stated as

$$
\pi^{e}=\pi \text {. }
$$

Taking into account that $\dot{m}=m_{\pi^{e}}^{\prime} \dot{\pi}^{e}$ we arrive at differential equations of inflation dynamics for the case of adaptive expectations (equation [4]) and the case of perfect foresight (equation [5]):

$$
\begin{aligned}
& \dot{\pi}=\frac{\theta}{1-\alpha \theta} \frac{D-\pi m(\pi)}{m}, \\
& \dot{\pi}=-\frac{1}{\alpha} \frac{D-\pi m(\pi)}{m},
\end{aligned}
$$

where $\alpha=-m_{\pi^{e}}^{\prime} / m>0$ is the semi-elasticity of money demand with respect to expected inflation rate. This parameter is constant for the Cagan demand function that is very often assumed in the literature on high inflation.

For a given constant level of operational budget deficit that does not exceed the maximum inflation tax, there are two steady state levels of inflation (see Fig. 1). If expectations are adaptive and $\alpha \theta<1$ (i.e. expectations slowly adjust to the actual rate of inflation and the sensitivity of the demand for money to inflation is low), then low inflation is the stable steady state and high inflation is the unstable steady state. ${ }^{9}$ However, if $\alpha \theta>1$ or if expectations are rational (the case of perfect foresight), then low inflation is the unstable steady state and high inflation is the stable steady state. That is, the economy falls into the so-called "high inflation trap". This result is puzzling. As long as the adaptive expectations hypothesis is usually rejected as an unappealing behavioral assumption allowing for a systematic prediction error, a high inflation trap is the outcome of the model. ${ }^{10}$ However, this means that the monetization of even a very low budget deficit will inevitably produce

\footnotetext{
${ }^{9}$ Similar result can be obtained under the assumptions of perfect foresight and the slow adjustment of the money market (see, e.g., Kiguel, 1989).

${ }^{10}$ Sargent and Wallace (1987) interpret transitory dynamics toward high inflation equilibrium governed by rational expectations as a path to hyperinflation. This result is often referred as a "bubble explanation": during hyperinflation money supply typically accommodates inflation (Sargent and Wallace, 1973a). Imrohoroglu (1993) and Engsted (2003) provide empirical evidence on this view.
} 
very high inflation and that an increase in budget deficit will result in a decrease in inflation on the wrong side of the ITLC. This also means that if the budget deficit is higher than the maximum of the inflation tax, then the economy will face a hyperdeflation (not a hyperinflation!).

This problem has two general solutions. ${ }^{11,12}$ The first solution is to reinterpret the dynamic properties of the system. Actually, a high inflation trap results from the backward-looking approach to the dynamics of inflation under the assumption of perfect foresight. As was first shown by Sargent and Wallace (1973b) the dynamics of inflation in the monetary model is stable under rational forward-looking expectations. In this case the dynamics of inflation is determined by expectations about future monetary policy, which may themselves depend on future budget deficits that need to be covered by seigniorage. Unfortunately, this approach may be rather unappealing in application to the environment of extremely volatile high inflation and uncertain or hardly credible future macroeconomic policy.

The second solution is to use the more appealing assumption of adaptive learning instead of pure adaptive expectations. As was originally shown by Marcet and Sargent (1989), in this case the low inflation equilibrium is stable and, if the budget deficit exceeds maximum inflation tax, then the economy is prone to explosive hyperinflation. ${ }^{13}$ This avenue of research seems prominent. In a response to general criticism of the models with bounded rationality, ${ }^{14}$ Marcet and Nicolini (2003) provide a model with restricted learning mechanisms that allow expectations to be endogenous to policy switches. In their model the low inflation equilibrium is also stable. However, even if one takes this more general assumption of bounded rationality, which guaranties the stability of the low inflation equilibrium, the basic model can not be used as a universal explanation of different economic outcomes. As we noted earlier, there is significant evidence that in times of high or hyperinflation economies often operate on the wrong side of the ITLC. Thus, a model that selects the low inflation equilibrium as the stable one can not explain this phenomenon, nor can a model with a stable high inflation on the wrong side account for low inflation episodes. Thus, one needs a model that can imply stable low inflation equilibrium when the economic environment is stable and

\footnotetext{
${ }^{11}$ As noted by Marcet and Nicolini (2005) the apparent solution to the problem (to assume that agents in high inflation economies are rational while agents in low inflation economies form expectations adaptively) is unacceptable.

${ }^{12}$ Rodriguez-Arana (2007) provides a model of budget deficit finance in which the utility of money is insatiable (this comes from an interpretation of Keynes' ideas). The model implies properties of the Laffer curve and stability characteristics that are opposite to those of traditional analysis. In particular, a low inflation equilibrium may be associated with the increasing part of the Laffer curve. However, this actually creates an additional puzzle, not a solution.

${ }^{13}$ Marimon and Sunder $(1993,1994)$ provide experimental evidence for the stability of the low inflation steady state under adaptive learning. Evans, Honkapohja and Marimon (2001) extend the model to account for heterogeneous learning rules and stress the role of constraints on fiscal policy in convergence to low inflation equilibria.

${ }^{14}$ Sargent (1993) criticizes models with adaptive learning procedures for their arbitrariness. Also, basic learning algorithms that do not take into account reaction to changes in economic policy are subject to Lucas' critique.
} 
the budget deficit is low enough and stable (moderate or extremely) high inflation equilibrium when the financial system is unstable and the budget deficit is high. ${ }^{15}$

To solve this problem Marcet and Nicolini (2003) consider a setup in which the government finances the budget deficit by seigniorage only when inflation is below some certain limit and establishes a fixed exchange rate regime otherwise to stabilize hyperinflation. They assume that expectations are not rational, but only small deviations from rationality in adaptive learning are allowed. The model implies that low inflation equilibrium is locally stable but different shocks may push inflation rate out of the region that allows the restricted adaptive learning mechanism to bring the economy to the low inflation equilibrium. ${ }^{16}$ While this approach meets some stylized facts on recurrent hyperinflations in high inflation economies, it relies on the assumption that government can temporarily stabilize hyperinflation by setting an exchange rate peg that is rather arbitrary and does not deal with the underlying problem of budget deficit finance. ${ }^{17}$

There is another direction in economic literature that treats the high inflation trap not as an outcome of an expectations formation mechanism associated with a dual equilibria, but as an outcome of policy games. Zarazaga (1995) provides a game theoretic model in which several policymakers compete for seigniorage revenue to finance their specific spending under incomplete information that results in "megainflation" outbursts. Heymann and Sanguinetti (1994) emphasize the distinction between the "target" and "observed" level of public expenditures. High target expenditures may provoke high inflation expectations. However, when high inflation is present, inflation tax decreases along the wrong side of the ITLC that forces the government to cut its expenditures. Thus, the observed low deficit and high inflation are consistent with each other. Moreover, to fight high inflation one must think about the "target" level of expenditures (not "observed"!) that indicates "fiscal pressure". In this paper we also explore the difference between "attempted" and "observed" fiscal policy where the former is described by "zero-inflation-deficit", and the later is described by actual deficit that is partially eroded by inflation under the Patinkin effect.

\footnotetext{
${ }^{15}$ Moreover, it is better if the model can rule out explosive inflation dynamics. The reasoning is the same: depending on the assumption of expectations, the basic model can produce explosive hyperinflation or explosive hyperdeflation. Thus in the context of the ITLC model it is better to have the general explanation of extremely high inflation as a stable steady state.

${ }^{16}$ Marcet and Nicolini (2005) evolve this approach by considering a switching regime for exogenous money growth. Building on Marcet and Nicolini (2003), Sargent, Williams and Zha (2005) develop and empirically evaluate a nonlinear general equilibrium model of hyperinflation. They show the importance of different shocks to seigniorage and agent's beliefs when average seigniorage is high. Contrary to Bruno and Fischer (1990) they show that fiscal anchors matter.

${ }^{17}$ This methodology is in a line with the Michael Bruno's (Bruno, 1989) suggestion to solve the problem of "high inflation traps" by assuming that the speed of adaptation of expectations increases with inflation. Thus to escape from the trap and converge to low inflation equilibria, a policymaker can apply a price-wage freeze.
} 
Money demand, inflation and the budget deficit: is there a stable relation?

Despite the cross-country evidence of a strong positive relationship between the budget deficit and inflation during high inflation episodes (see, for example, recent evidence in Fischer, Sahay and Vegh, 2002; and Catão and Terrones, 2005), case studies show that the relationship between the budget deficit, seigniorage and inflation is not always strong and positive. There are several explanations for this fact: it may be due to lags in the reaction to changes in fiscal balance, inflationary persistence, etc. One should also note that the ITLC model implies a positive relationship between the budget deficit and inflation only for steady states on the efficient side of the Laffer curve. If the economy is on the wrong side of the ITLC, then the model actually implies a negative relationship between the budget deficit and steady state inflation. If the economy is not in the steady state, the budget deficit is financed by inflation tax and pure seigniorage, which may be either positive or negative and this complicates the analysis. Moreover, if the actual budget deficit is a decreasing function of inflation due to the Patinkin effect, then an attempted fiscal expansion actually may lead to a lower budget deficit. Thus the effect of an attempted fiscal expansion on the inflation rate is ambiguous.

The failure to find a strong positive relationship between the budget deficit and inflation may be also due to unaccounted shifts in the velocity and misspecification of the money demand function. ${ }^{18}$ In his seminal work Cagan (1956) assumed a stable demand for money with constant semi-elasticity of money demand with respect to expected inflation. While this log-linear specification is still attractive for analytical reasons and may be seen as a special case that can be derived from the micro-founded model (see Calvo and Leiderman, 1992), recent research reveals that semi-elasticity of money demand is not constant. In point of fact, research in this field is not extensive and it seems to constitute a kind of controversy. On one hand, Easterly, Mauro and Schmidt-Hebbel (1995) provide a model and empirical evidence based on a sample of high inflation economies that the semi-elasticity of money demand with respect to inflation increases with the rate of inflation. This fact has dramatic implications for the determination of the seignioragemaximizing rate of inflation and the existence of the Laffer curve effect. It also implies that eventually an increase in the semi-elasticity can make the maximum inflation tax smaller than the continuing budget deficit. On the other hand, Michael, Nobay and Peel (1994) and Petrović and Mladenović $(2000,2006)$ provide evidence that the semi-elasticity of money demand decreased during the final months of hyperinflation in Germany (1921-1923) and Yugoslavia (1991-1993). They interpret this result as a solution to Cagan's paradox: decreasing semi-elasticity implies a

\footnotetext{
${ }^{18}$ Engsted $(1993,1994)$ shows the importance of velocity shocks in empirical investigations of classical hyperinflations. Particular causes of shifts in money demand are: changes in reserves requirements that represent a common element of monetary policy in high inflation economies (Bali and Thurston, 2000); specific measures of financial repression or liberalization (Calvo and Leiderman, 1992; Altinkemer, 1994); or broadly defined financial innovations (Arrau et al., 1995).
} 
higher seigniorage-maximizing rate of inflation, and so the economy may well be on the increasing branch of the Laffer curve during hyperinflation. This diverse evidence demands further investigation. One possible explanation of this apparent controversy is the institutional difference between chronically high inflation economies studied by Easterly, Mauro and Schmidt-Hebbel (1995) and hyperinflation outbursts in previously financially stable economies, studied by Michael, Nobay and Peel (1994) and Petrović and Mladenović $(2000,2006) .{ }^{19}$ The fact that the semielasticity of money demand increases with the rate of inflation may correspond to simple intuition as it implies intensifying the "run from money" effect and leads to a shrinking of the inflation tax's base. Petrović and Mladenović (2000) explain the decrease in semi-elasticity during the final months of the Yugoslavian hyperinflation by using micro-foundations for the demand for real money balances developed in Calvo and Leiderman (1992). In their analysis, the semi-elasticity of money demand is determined by the output to consumption ratio. As long as hyperinflation is usually accompanied by a sharp recession during which output falls more than consumption, semielasticity may actually decrease.

\section{The model of budget deficit monetization under a linear inflation effect}

The assumption that the deficit is exogenous and independent of inflation - and therefore the accompanying assumption that the deficit finance by seigniorage is likewise independent of inflation, which was used implicitly above - is not always realistic. There are many factors that can bring about either a decrease or an increase in the real primary budget deficit $d$ under inflation. The first group of factors include the increase of real tax revenues for the budget as a result of applying a progressive income tax scale in nominal terms (with discrete indexes) or because of the distortionary nature of taxing the nominal interest income; the decrease in the real volume of transfers and government expenditures given in nominal terms (and with non-continuous indexation), the Patinkin effect. ${ }^{20}$ The second group of factors should include, first of all, the Olivera-Tanzi effect. This effect consists in a decrease in the real revenue volume and an increase in

\footnotetext{
${ }^{19}$ Alternatively, it may imply that the semi-elasticity of money demand with respect to inflation is a nonlinear function of inflation, increasing when inflation is in the moderate or high range and decreasing when economy falls into hyperinflation. Note that modeling demand for real money balances with increasing or decreasing semi-elasticity does not imply shifts in the inflation tax Laffer curve following a switch in the inflationary regime as inflation increases.

${ }^{20}$ Cardoso and Helwege (1999) provide a detailed description of these factors.
} 
the real deficit, which takes place because a significant part of the taxes and other budget incomes are determined in nominal terms and often reach the budget with a given time lag. ${ }^{21}$

In the general case, of course, it is difficult to determine which factors play the greater role and how the primary budget deficit will depend on the inflation rate in the final analysis. However, it can be sometimes observed in practice. Indeed, the Olivera-Tanzi effect is very often mentioned in the literature on high inflation economies. Unfortunately, and probably misleadingly, the opposite effect has attracted little attention so far. For instance, Gavrilenkov (1995) noted a tendency in Russia for a softening of the budget deficit with an increase in inflation, while Cardoso (1998) stress the important role of the Patinkin effect for the case of Brazil.

Usually researches mention the feedback from inflation to budget deficit simply to stress that inflation affects everything. However, is it just an auxiliary assumption that does not change the principle mechanism of inflationary finance? To answer this question let us assume that $D=D(\pi)$ in the ITLC model introduced earlier. If the Olivera-Tanzi effect is dominant in the economy, that is if $D^{\prime}(\bullet)>0$, then the budget deficit curve will have a positive slope. Fig. 1 illustrates this possible situation. Indeed in this case it seems most likely that the Olivera-Tanzi effect does not affect the principal result, namely that there are two steady states, the stability of which can be determined just as in the basic case. 22

If the Patinkin effect has the greater impact, i.e. $D^{\prime}(\bullet)<0$, then the budget deficit curve will have a negative slope. For simplicity, we start by considering the following simple linear specification:

$$
D(\pi)=d_{E}(1-\beta \pi)+d_{P} .
$$

Here, using Cardoso's terminology, $d_{0}=d_{E}+d_{P}$ represents the "virtual deficit" that would have been in the case of zero inflation. However, while Cardoso (1998) considers the whole budget deficit that is subject to the Patinkin effect, it seems to be more realistic to assume that only a certain part of this zero-inflation deficit, namely $d_{E}$, may be affected by inflation. We will term it "exposed deficit". The other part, $d_{P}$, represents "inflation-proof deficit" that is not subject to inflation feedback. In practice this division is determined by institutional arrangement. For example, $d_{E}$ may consist of expenditures of particular ministries whose bargaining power is too low to

\footnotetext{
${ }^{21}$ This list of factors, of course, is not meant to be complete. All of the factors in essence are distortional effects of inflation, determined by nominal state institutions. A brilliant overview of the real effects of inflation can be found in the paper by Fischer and Modigliani (1979).

${ }^{22}$ Fig. 1 illustrates the case when $D(\pi)$ is a linear function. Dornbusch, Sturzenegger and Wolf (1990) suggest the following specification of the Olivera-Tanzi effect: $D(\pi)=G-[T /(1+\sigma \pi)]$, where $G$ is government expenditures, $T$ is the tax revenue and the parameter $0 \leq \sigma<\infty$ characterizes the extent to which the Olivera-Tanzi effect influences the economy (its absence corresponds to a value of zero). It is not difficult to see that for this reasonable specification the system will also have two steady states.
} 
provide an indexation of their expenditures (as it was introduced by Patinkin, 1993). Inflation-proof deficit should include debt service in the case of foreign or indexed debt (that may be relatively large) among other items. Finally, the parameter $\beta$ characterizes the strength of the Patinkin effect.

Fig. 1 shows that up to three steady states are possible. For instance, if the inflation expectations are adaptive or near-rational (with some appropriate mechanism of adaptive learning), the states with low or extremely high (hyper-) inflation are stable, while the equilibrium that corresponds to the middle inflation is unstable. ${ }^{23}$ It is important to note that this model rules out explosive hyperinflation (or hyperdeflation): no matter how high the budget deficit is, there is always at least one stable equilibrium with extremely high (hyper-) inflation.

One purpose of this paper is to reinterpret the evidence of the weak (at least instantaneous) correlation between budget deficits and inflation. Thus the next step is to see what the impact of fiscal policy upon inflation is under different regimes. In principle, changes in both exposed and inflation-proof parts of the total deficit can be interpreted as fiscal expansion. However, as we will see, they operate in very different ways and thus they should be studied separately. Following the insight of Heymann and Sanguinetti (1994) we can state that changes in different items of the budget balance sheet may have very different effects on inflation (apart from their different effects on the real economy). If this is true, then the common practice to search for inflationary effects of fiscal policy using aggregate budgetary statistics may be somehow misleading. It has also an important implication for the design of stabilization programs: in a situation when it is harmful to cut any spending items or to raise tax revenues, what are the expenditures that should be cut first? In other words, is it exposed deficit or inflation-proof deficit that should be cut first to stabilize extremely high inflation? We will to explore this problem below.

\section{Changes in exposed budget deficit}

We will consider first the effect of increasing the exposed deficit $d_{E}$, keeping inflation-proof deficit constant. Note that an increase in $d_{E}$ does not simply move up the line described by equation (6), but it pivots this line around point $E$ with coordinates $\left(1 / \beta, d_{P}\right)$ as shown in Fig. 1 . Thus the number and stability of equilibria and the corresponding vector field crucially depend on the

\footnotetext{
${ }^{23}$ The coexistence of two stable (and obviously Pareto-ranked) equilibria in this model opens up two seemingly prominent avenues of research that are beyond the scope of this paper. First, there could be a room for the monetary anchors that act to bring the economy to the low inflation equilibria along the lines suggested by Bruno and Fischer (1990). Second, the situation when the economy falls into the Pareto-inferior equilibrium with extremely high inflation may be interpreted as an outcome of specific "coordination failure". It can be modeled as a policy game between the central bank that prefers low inflation and the government that is biased towards high "virtual deficit" partially wiped out by inflation. Another possibility is to consider (following Zarazaga, 1995) the struggle between different budget agencies that have to either accept low level of expenditures (and thus low inflation) initially, or to ask for the finance of high expenditures and see how the resulting high inflation will erode them.
} 
position of $E$ with respect to the ITLC. Fig. 2 shows that there are eleven more or less different cases. The corresponding bifurcation diagrams are described in Fig. 3.

We can see that this rather simple model of inflationary finance surprisingly gives rise to many different bifurcation maps. Most of the diagrams demonstrate the coexistence of a fold bifurcation and the stable branch. Exceptions are Fig. 3.5, where there is no bifurcation at all and Fig. 3.8, which exhibits the case of a pitchfork bifurcation. Also, Fig. 3.6 and Fig. 3.10 demonstrate a combination of fold and transcritical bifurcations. Fig. 3.4, Fig. 3.7 and Fig. 3.10 indicate the existence of hysteresis (a double fold bifurcation). The main reason for this rich pattern is the combination of a downward sloping budget line and a hump shape of the ITLC. In particular, it is important that there is an inflection on its wrong side (the pitchfork bifurcation in Fig. 3.8 corresponds exactly to this point).

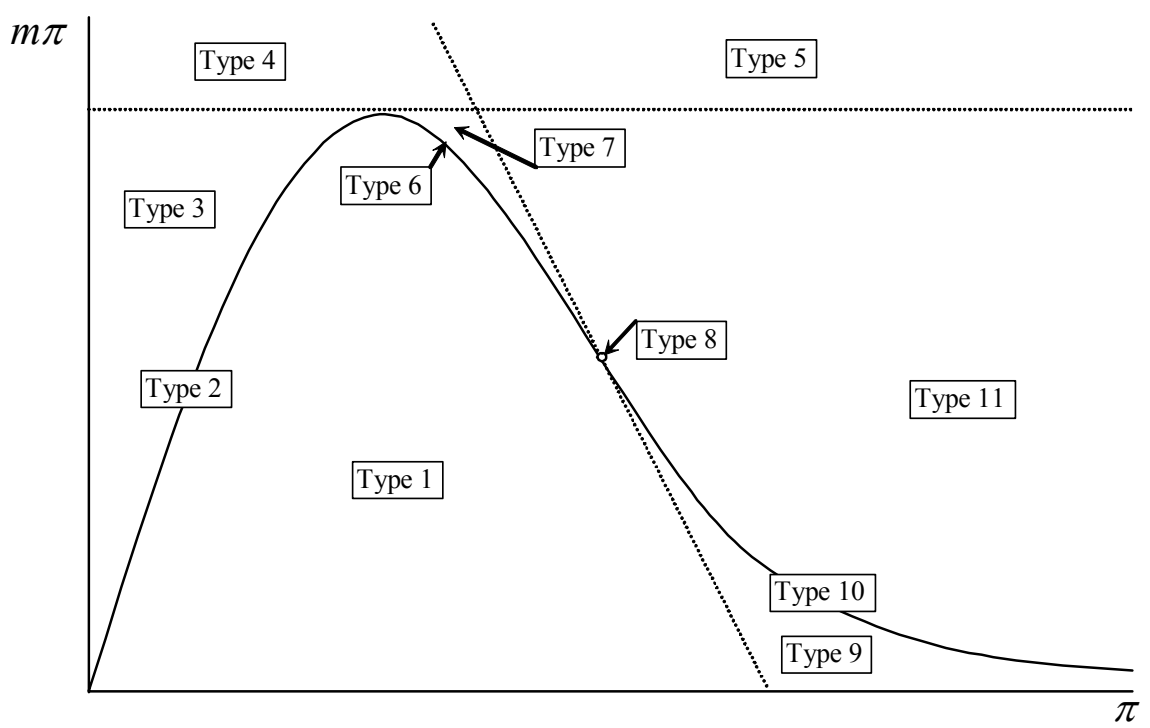

Fig. 2. Determination of different types of bifurcation

Before we consider certain general and particular implications of these bifurcation diagrams, we briefly discuss the plausibility of all these cases. The question is, do all the regions in Fig. 2 provide a plausible location of point $E$ ? The answer is positive, with the exception of the regions close to the ordinate axis that correspond only partially to the cases described in Fig. 3.1-3.4. Indeed, the two factors that determine the position of point $E$ are the strength of the Patinkin effect and the size of the inflation-proof budget deficit. In this paper we do not attempt to give empirical estimations of the Patinkin effect, and to our knowledge this problem has not been considered in the literature. Therefore, we can only make conjectures on the basis of simple examples. If we take $\pi^{*}=1000 \%$ as a revenue maximizing rate of inflation (which is higher than Cagan's original estimate but which is nevertheless reasonable), then $\beta=0.1$ corresponds to the position of point $E$ 
with the axis coordinate equal to $\pi^{*}$. Smaller $\beta$ 's that characterize weaker Patinkin effects put the position of point $E$ to the right of the revenue maximizing rate of inflation, while higher $\beta$ 's (a stronger Patinkin effect) place point $E$ to the left of $\pi^{*}$. This value of $\beta=0.1$ means that at 100 percent annual inflation rate only 10 percent of the real primary budget deficit is deteriorated. An even stronger Patinkin effect (say, $\beta=0.2$, corresponding to the position of point $E$ at $\pi=500 \%$ ), that deteriorates 20 percent of the real primary budget deficit at an annual inflation rate equal to 100 percent may be quite plausible in countries with weak government institutions. As for the second factor, inflation-proof deficit could be relatively small or relatively large. In the framework of this model it can be even higher than the maximum inflation tax. Thus, from this standpoint, all cases shown in Fig. 3 deserve attention. However, there is yet an additional consideration that stems from the usage of the linear form (6). Given even a large virtual deficit, this assumption allows inflation to create an actual budget surplus if $\pi>1 / \beta$. In actuality, this may be realistic only to some extent. Thus, the results that are obtained under assumption of a very strong Patinkin effect suffer from this point.

General results that we learn from this variety of bifurcations are the following:

Multiplicity and stability of equilibria. The system may have up to three steady states. In fact, the existence of three steady states seems to be the most typical and plausible outcome. In this case low inflation and extremely high (hyper-) inflation steady states are stable, while the medium steady state is unstable.

In the basic model with exogenous (constant) budget deficit terms the "low inflation equilibrium" and the "high inflation equilibrium" correspond precisely to steady states that are on the increasing and decreasing branches of the ITLC respectively. ${ }^{24}$ However, in this model, as far as a declining deficit line is considered, the term "low inflation equilibrium" does not always correspond only to the increasing branch of the ITLC. The horizontal chain lines in Fig. 3 (and in Fig. 4 and Fig. 6 below as well) correspond to the rate of inflation that maximizes the inflation tax. $^{25}$ The low inflation steady state may be on the decreasing branch of the ITLC as well. Only when point $E$ is posited south-west to the peak of the ITLC (i.e. $1 / \beta<\pi^{*}$ and $d_{P}<\pi^{*} m\left(\pi^{*}\right)$ ), will the low inflation steady state always be on the increasing branch of the ITLC.

\footnotetext{
${ }^{24}$ As in the basic model here we use the terms "low inflation equilibrium" or "low inflation branch" to denote a particular steady state with the lowest inflation rate among others. It does not mean literally that the inflation rate is low by international standards.

${ }^{25}$ In the cases depicted in Fig. 3.1 and Fig. 3.4 there are two possible positions of this line with respect to the low inflation branch. For exposition, the scale of the ordinate line varies across different cases depicted in Fig. 3 (the chain line appears at visually different levels).
} 

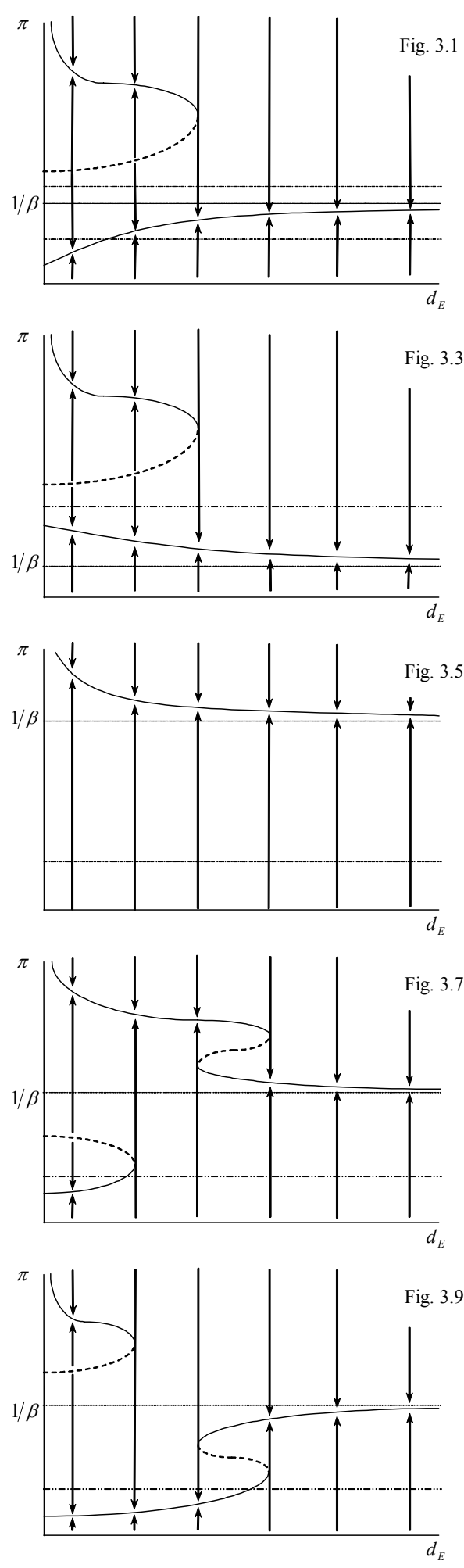
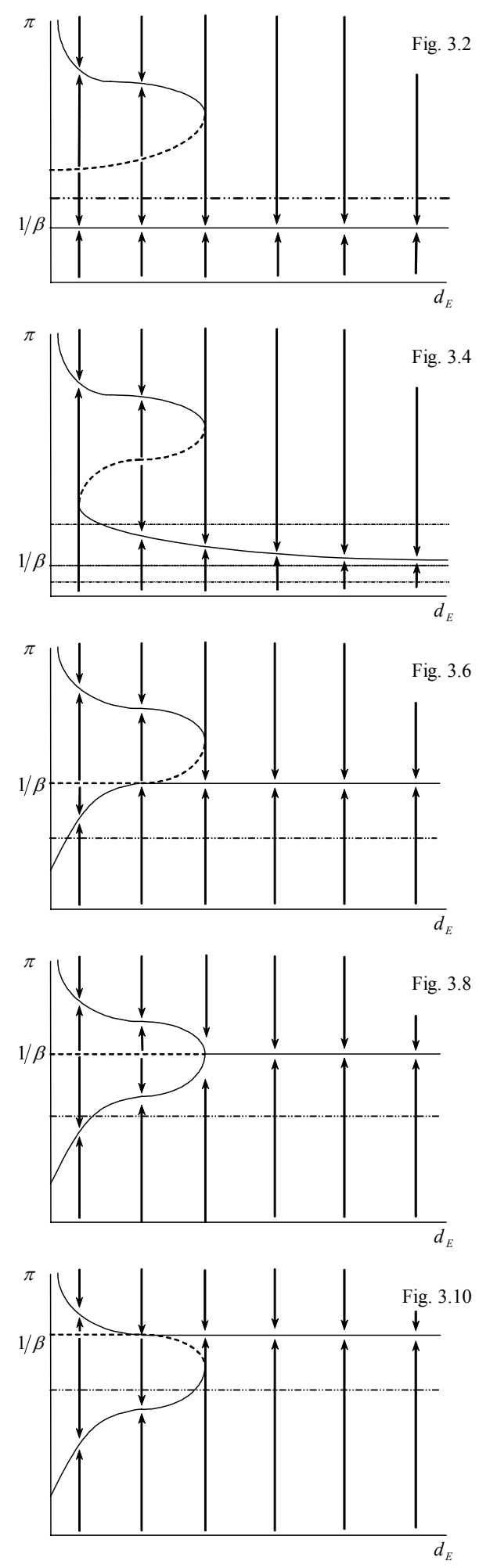

Fig. 3.11

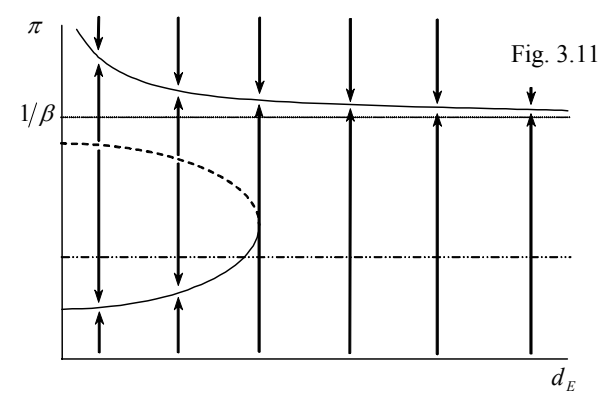

Fig. 3. Bifurcation diagrams for the change in parameter $d_{E}$

16 
For all positive values of the exposed deficit $d_{E}$, the system has a stable steady state with extremely high (hyper-) inflation. When $d_{E}$ is very high this is the only steady state. In other words, this model rules out explosive hyperinflation (or hyperdeflation). This is because extremely high inflation can actually produce a negative value of $d_{E}(1-\beta \pi)$, which is a partial surplus. Thus the operational balance $d_{P}+d_{E}(1-\beta \pi)$ is sufficiently reduced to be financed by shrinking inflation tax revenues.

Except for the cases shown in Fig. 3.5 and (to a certain extent) in Fig. 3.4, a relatively low level of exposed deficit $d_{E}$ guarantees the existence of a stable low-inflation steady state. In this respect we can treat the "high inflation trap" only as a local phenomenon (locally stable steady state). This result contrasts with the basic finding of the ITLC model with rational expectations, where a high-inflation steady state is globally stable.

How to reduce inflation by the means of exposed deficit? The natural question that arises here is whether it is possible to move the economy from the extremely high (hyper-) inflation stable steady state to a low inflation stable steady state if both of them exist. As can be seen from Fig. 3, an attempted fiscal contraction in the form of a reduction of the exposed deficit $d_{E}$ cannot always produce this shift alone. ${ }^{26}$ In fact, if the economy is trapped in the extremely high (hyper-) inflation steady state, then a reduction in $d_{E}$ leads to a further increase in inflation. There are two factors that explain this phenomenon. The first is the well-known effect associated with the wrong side of the ITLC, where a decrease in revenue requires an increase in the tax rate (inflation rate). The second is the specific arithmetic of the Patinkin effect. It is easy to see that in the extremely high (hyper-) inflation equilibrium, the inflation-proof deficit (that is, the ordinate of point $E$ ) is always higher than the inflation tax, $d_{P}>\pi m(\pi)$. This is only possible in the steady state if $d_{E}(1-\beta \pi)<0$. That is, the Patinkin effect creates a surplus, $1-\beta \pi<0$. However, as long as $d_{E}>0$, its decrease must be balanced by an increase in the inflation rate. ${ }^{27}$

Surprisingly, Fig. 3 demonstrates that in most cases (except for those corresponding to Fig. $3.5,3.10$ and 3.11) the government has to increase (not decrease!) the exposed budget deficit $d_{E}$ to move the economy from the extremely high (hyper-) inflation stable steady state to the low inflation stable steady state. The explanation of this seemingly paradoxical result lies in the logic described

\footnotetext{
${ }^{26}$ Exceptions can be found in Fig. 3.9 and 3.10, but even in these cases the jump from high to low inflation occurs at relatively high levels of exposed deficit. When it is relatively low, its decrease cannot move inflation from the extremely high (hyper-) to the low inflation branch.

${ }^{27}$ We are not concerned with an unstable branch of equilibria. However, it is interesting to note that due to the existence of the Patinkin effect an increase in the exposed deficit does not always lead to a decrease in the middle steady state inflation rate despite the arithmetic of the wrong side of ITLC. Indeed, the unstable middle steady state is always on the wrong side. However, this unstable branch may be either decreasing, or increasing.
} 
in the previous paragraph. An additional element that explains the bifurcation phenomenon consists in the following. Consider inflation as a function of exposed deficit given other parameters. Note that the absolute value of expression $d_{E}\left(1-\beta \pi\left(d_{E}\right)\right)$ is a hump-shaped function of $d_{E}$. In other words, it demonstrates its own Laffer curve property. When $d_{E}$ increases, the middle unstable steady state and the stable steady state with extremely high (hyper-) inflation move towards each other and eventually collapse in the bifurcation point. A further increase in $d_{E}$ cannot provide sufficient partial surplus (equal to $d_{E}\left(1-\beta \pi\left(d_{E}\right)\right.$ ), which is negative and sufficiently high in absolute value), any more. The only remaining possibility for stable finance is the position on the low inflation branch, where $d_{P}<\pi m(\pi)$ and thus $d_{E}(1-\beta \pi)>0$ (the Patinkin effect still works but does not create a surplus). ${ }^{28}$

To summarize the findings in two previous paragraphs we can state the following implication of the model: if one considers the exposed deficit as the sole stabilization tool, then its effect is associated with a certain type of hysteresis. A government that is attempting to stop extremely high (hyper-) inflation finds itself trapped in a situation when it can not simply give up the exploitation of the Patinkin effect (this creates a partial surplus) by reducing exposed deficit once this mechanism is in place. The only way to switch to the other regime (where the Patinkin effect does not create a partial surplus) is to exploit the previous regime to its limit.

Is there an unambiguous relationship between (exposed) deficits and inflation? The relationship between $d_{E}$ and inflation is negative (not positive!) when the economy is in the extremely high (hyper-) inflation steady state posited on the wrong side of ITLC. Moreover, Fig. 3 demonstrates that this relationship is ambiguous even when the economy is on the efficient side of the ITLC (Fig. 3.3 and Fig. 3.4 demonstrate the decreasing low inflation branch). At the same time, as long as the actual deficit should be equal to inflation tax in the steady state, the relationship between the actual budget deficit and inflation is always positive on the efficient side of ITLC and negative on its wrong side. However, unlike the basic model with an exogenous budget deficit, here the arithmetic of the wrong side provides only a partial explanation for the negative relationship between the budget deficit and inflation. An exhaustive explanation would require the Patinkin effect to be taken into account.

There are two considerations that underline this ambiguity. First, it is necessary to clearly distinguish virtual (zero-inflation) and actual budget deficits, since the former mostly indicates the attempted fiscal policy, while the latter characterizes the actual result that takes into account

\footnotetext{
${ }^{28}$ The same logic may also explain why the cases illustrated in Fig. 3.4 and Fig. 3.5 do not have a low-inflation stable equilibrium.
} 
inflation feedback. Furthermore, due to the "wrong side effect" and the Patinkin effect, neither the attempted nor the actual fiscal contraction is always able to reduce inflation. Second, there is a general problem of steady state analysis and the usage of discrete data from the budget balance sheet. The Patinkin effect does not decreases the budget deficit all at once, but rather gradually over the time. Thus, analysis across steady states and the empirical search for a relationship between the budget deficit and inflation may be misleading in their interpretation of how important the Patinkin effect is.

\section{Changes in the inflation-proof budget deficit}

Let us now turn to the analysis of the consequences of changes in the part of the monetized operational deficit that is not deteriorated by inflation. This part can consist of different items. Obviously, in high inflation countries the debt service (assuming that the real value of the debt is indexed or that it is denominated in foreign currency) deserves special attention. In general, public debt is a dynamic variable, yet in our reduced model we can consider debt service as a bifurcation parameter. Changes in debt service may be caused by changes in fiscal rules, according to which a certain part of operational deficit is monetized if, for example, the government can not roll over its debt further in the face of a confidence crisis. Alternatively, these changes may be due to shifts in the exogenous interest rate, which may rise following the same reason: a confidence crisis, when investors are ready to buy new debt only at a higher interest rate. Another important possibility is that the government may guarantee private debt that represents implicit liabilities in good times, but become an explicit part of public debt in time of crises, and this leads to a discrete increase in debt service. On the other hand, debt service may decrease if there is a restructuring of debt or debt relief.

Changes in the inflation-proof deficit $d_{P}$ result in a parallel shift of the budget deficit line described by equation (6). There are two cases that correspond to two different bifurcation diagrams in Fig. 4. If the budget deficit line is flatter than the slope of the ITLC in its inflection point at the wrong side, then depending on the size of $d_{P}$ there could be one, two or three steady states. The bifurcation diagram (Fig. 4.1) shows that there is a hysteresis with two fold bifurcations. However, if the budget deficit line is steeper than the slope of the ITLC at the inflection point, then for any $d_{P}$ there is always one steady state rate of inflation (Fig. 4.2). The slope of the budget deficit line is equal to $-\beta d_{E}$. It can be easily seen that for constant semi-elasticity Cagan's money demand, $m=A e^{-\alpha \pi}$, where $A>0$ is a scale parameter, the inflection point corresponds to $\pi^{* *}=2 / \alpha$, and the slope of the ITLC at the inflection point is equal to $-A e^{-2}$ and does not depend on the value of semi-elasticity. Thus, Fig. 4.1 corresponds to the case when the exposed deficit $d_{E}$ is relatively 
small and the Patinkin effect is relatively weak, while Fig. 4.2 corresponds to the case when the exposed deficit is relatively large and the Patinkin effect is relatively strong. ${ }^{29}$

Comparing these different cases, we see that in the case of a relatively large exposed deficit and a strong Patinkin effect, changes in the size of the inflation-proof deficit $d_{P}$ do not have a strong stabilizing or destabilizing effect. However, if the exposed deficit is small enough and the Patinkin effect is weak, then an increase in $d_{P}$ over a critical level leads to an abrupt change in the inflationary regime, moving the economy from high inflation to hyperinflation. If the economy suffers from extremely high (hyper-) inflation, then a sufficiently large decrease in the size of the inflation-proof deficit may stop extreme inflation (hyperinflation) and move the economy to the low inflation branch. ${ }^{30}$
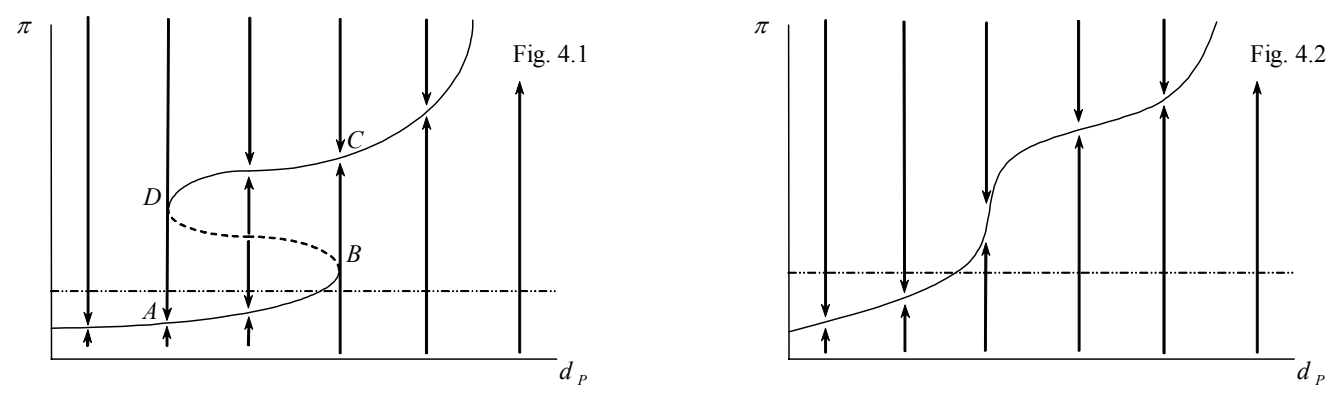

Fig. 4. Bifurcation diagrams for the change in parameter $d_{P}$

There are three major conclusions.

Inflation-proof deficit and inflation. While the relationship between the exposed budget deficit and a stable inflation rate was ambiguous, the relationship between the inflation-proof deficit and a stable inflation rate is always positive, though nonlinear. Furthermore, this is true no matter what side of the Laffer curve the economy is operating on. Actually, the part of the low inflation branch in Fig. 4.1 falls into the wrong side, while the entire extremely high (hyper-) inflation branch is on the wrong side.

Recurrent hyperinflations. This model can explain the well-known phenomena that (chronically) high inflation economies often fall into the hyperinflation regime for some period and than return to moderate inflation. These catastrophic (rapid) changes in the regime may occur even without visible deterioration or an improvement in economic conditions.

So far as even small changes in the size of the inflation-proof deficit (in particular, in the size of debt service) can lead to abrupt change in the regime, various things such as publicly guaranteed

\footnotetext{
${ }^{29}$ In the general case, the slope of the ITLC at the inflection point may depend on the semi-elasticity, which in turn may depend on the properties of the utility function, income and consumption. See Calvo and Leiderman (1992). Thus in general the existence of the hysteresis effect in Fig. 4.1 depends on these factors as well.

${ }^{30}$ Remember that term "low inflation branch" corresponds to the lower equilibrium, but it does not literally mean low rates of inflation.
} 
debt (implicit government liabilities) or debt relieves, changes in investor confidence that affect the interest rate, the appearance or disappearance of the indexation of government spending, are all important in understanding the causes of recurrent hyperinflations and their stabilization.

Hysteresis. The explanation of why chronically high inflation countries sometimes fall into the hyperinflation regime involves the important hysteresis effect. Consider the low inflation branch $A B$ and the extremely high (hyper-) inflation branch DC in Fig. 4.1. Assume that the economy is initially in point $A$ in Fig. 4.1. A small increase in $d_{P}$ initially leads to a gradual increase in the inflation rate and does not produce an abrupt shift unless the economy reaches point $B$. In point $B$, which is actually on the wrong side of the Laffer curve (where the inflation rate is indeed very high by international standards), there is a discrete jump in inflation that moves the economy to point $C$ at the extremely high (hyper-) inflation branch. However, when the economy is in point $C$, a small decrease in the inflation-proof deficit cannot produce a downward jump in inflation to the low inflation branch (say, back to point $B$ ). It can produce a relatively small decrease in inflation along the branch $D C$. Only when the inflation-proof deficit $d_{P}$ is significantly reduced, so that the economy has moved to point $D$, will there be a downward jump in inflation (a jump from point $D$ to point $A$ ). Again, when the economy is in point $A$, it will not jump to the extremely high (hyper-) branch, unless $d_{P}$ increases by too much.

The intuition behind the hysteresis effect is again based on the operation of the Patinkin effect and the arithmetic of the wrong side of ITLC. As long as stable inflation rate is an increasing function of the inflation-proof deficit $d_{P}$, an increase in the latter has two effects upon the total budget deficit $D(\pi)=d_{E}\left(1-\beta \pi\left(d_{P}\right)\right)+d_{P}$. The first is a direct effect of an increase in $D(\pi)$ following an increase in $d_{P}$. The second effect is the reduction of $d_{E}\left(1-\beta \pi\left(d_{P}\right)\right)$ due to the Patinkin effect. Note also that when the economy is on the efficient side of the ITLC, an increase in $d_{P}$ (which leads to an increase in inflation) is associated with an increase in inflation tax revenue, which is used to finance the rising $D(\pi)$. However, when the economy eventually slips into the wrong side, a further increase in $d_{P}$ and inflation leads to a smaller inflation tax revenue. This can be observed in a steady state only for the smaller values of $D(\pi)$ that resemble the arithmetic of the wrong side. The question is whether the situation of increasing $d_{P}$ and decreasing $D(\pi)$ (which is financed by steady state seigniorage) is feasible along the whole wrong side of ITLC. The answer is that this is indeed feasible if the Patinkin effect is strong enough; this is explained in the next paragraph. However, when the Patinkin effect is weak, this situation is feasible only for the upper and lower segments of the wrong side. For the middle segment (which is associated with a relatively sharp decline in the inflation tax following an increase in the inflation rate) it is not 
feasible. This makes the corresponding steady states unstable. Indeed, for the sharp decline in $D(\pi)$ that is needed to meet rapidly falling inflation tax revenues, there needs to be a strong Patinkin effect to override the increase in the inflation-proof deficit. Otherwise, a decline in $D(\pi)$ can be met by inflation tax finance only if the latter is a rather steep function of inflation (and this is the case for the upper and the lower segments of the wrong side).

The case shown in Fig. 4.2 does not demonstrate the hysteresis effect, but it resembles this nonlinearity. Here the steady state inflation rate is a monotonic function of $d_{P}$ that changes its convexity (it increases more rapidly over a certain interval). The reason why a relatively large exposed deficit and a strong Patinkin effect preclude the hysteresis effect associated with the changes in inflation-proof deficit is straightforward. On one hand, when the exposed budget deficit is high enough, it becomes a more important part of the total budget deficit that is financed by inflation tax. Thus, it outweighs the inflation-proof deficit in determining the steady state inflation rate. On the other hand, when the Patinkin effect is relatively strong, it can turn the exposed deficit into a surplus even at relatively low inflation rates. Given the size of the exposed deficit, an increase in the steady state inflation rate leads to an increase in the level of the resulting surplus. This balances the increase in the size of the inflation-proof deficit and makes its nonlinear effect weaker. However, in general, as long as a very strong Patinkin effect seems to be an unrealistic assumption and in practice governments do not design the zero-inflation budget deficit to be "extraordinarily" high even in face of a deep budget crisis, the case shown in Fig. 4.2 seems to provide a less realistic outcome than the hysteresis effect described in Fig. 4.1.

An important lesson that we learn in comparing the consequences of changes in the exposed deficit and of changes in the inflation-proof deficit is that the latter provides a more efficient fiscal instrument that can be used to stop extremely high (hyper-) inflation. Indeed, as shown in the previous subsection, a decrease in the exposed deficit leads to even higher rates of inflation once the economy is on the extremely high (hyper-) inflation branch. In contrast, a reduction in the inflationproof deficit leads to a gradual reduction in inflation that is likely to be followed by an abrupt downward jump in inflation after some critical point (or at least a rapid decrease in inflation if bifurcation does not occur).

\section{Shifts in money demand}

Unaccounted shifts in money demand seem to be important part of the explanation for the weak correlation between the budget deficit and inflation. Consider, for example, a decrease in the demand for real money balances (which could result after financial liberalization, allowing the substitution of domestic currency in transactions, etc.). A downward shift in demand for real money balances shrinks the base of inflation tax. The ITLC moves down for any given budget deficit line. 
In fact, this produces qualitatively the same picture as an upward shift of the budget line given the Laffer curve. As in the case of changes in the inflation-proof deficit, in this case shifts in money demand may be associated with the substantial hysteresis effect described in Fig. 4.1. A decrease in money demand, associated initially with the gradual increase in the inflation rate along the low inflation equilibrium branch, may produce an abrupt jump in inflation, moving the economy to the extremely high (hyper-) inflation branch. And once the economy is there, the demand for real money balances needs to rise substantially in order to return the economy to the low inflation branch. $^{31}$

This result corresponds to previous findings of the hysteresis effect in the money market in high inflation economies. Dornbusch, Sturzenegger and Wolf (1990) show that shifts in money demand in high inflation economies may represent an important hysteresis effect when money demand does not return to its low inflation level after stabilization. Arce (2006) provides a model of hyperinflation that incorporates this hysteresis effect. He shows that due to the hysteresis in money demand, fiscal-monetary reform that usually stops hyperinflation can not prevent its outburst from high inflation. However, unlike previous studies, the model presented here does not involve any specific mechanism that describes the adoption of new financial instruments. Instead, we provide an explanation based on the specific budgetary arithmetic of the Patinkin effect. In doing so, we do not call into question the importance of financial market mechanisms, but rather provide complementary explanation of the hysteresis.

\section{A model of budget deficit monetization under a nonlinear inflation effect}

The variety of different bifurcation scenarios described in the previous section can be seen as an outcome of introducing the Patinkin effect in a specific linear form. However, the most important implications of the analysis of the Patinkin effect seem to be rather robust to the choice of particular specification. To see this, consider the more general assumption about the inflation feedback to the real budget deficit:

$$
D(\pi)=G e^{-u \pi}-T e^{-w \pi}+d_{P} .
$$

Here we follow the assumption that the budget deficit may be divided into a part that is immune to inflation, $d_{P}$, and a part that is subject to inflation feedback. $G$ and $T$ denote government spending and tax revenue respectively. The term $e^{-u \pi}$ characterizes the Patinkin effect that deteriorates

\footnotetext{
${ }^{31}$ As the basic mechanics and the intuition are the same as for changes in the inflation-proof deficit, we do not plot the same (identical) figure.
} 
spending, while the term $e^{-w \pi}$ represents the Olivera-Tanzi effect that deteriorates tax revenue. ${ }^{32}$ The Patinkin effect is stronger than the Olivera-Tanzi effect if $u>w .^{33}$

Fig. 5 shows the form of the budget deficit curve (7) in this case. It is a decreasing function of inflation for $\pi<\tilde{\pi}=(u-w)^{-1}((\ln u-\ln w)+(\ln G-\ln T))$. For $\pi>\tilde{\pi}$ the budget deficit curve is an increasing function of $\pi$. As $\pi$ approaches infinity $D(\pi)$ approaches $d_{P}$ from below. It is straightforward to show that $\tilde{\pi}$ decreases with an increase in both parameters $u$ and $w$, while $D(\tilde{\pi})$ is a decreasing function of the difference $(u-w)$. The system may have up to four steady states. However, in the case of a very large exposed deficit $d_{E}=G-T$ and a large inflation-proof deficit $d_{P}$ there may be no steady state at all. That is, this nonlinear specification of the Patinkin effect does not exclude the possibility of explosive hyperinflation.

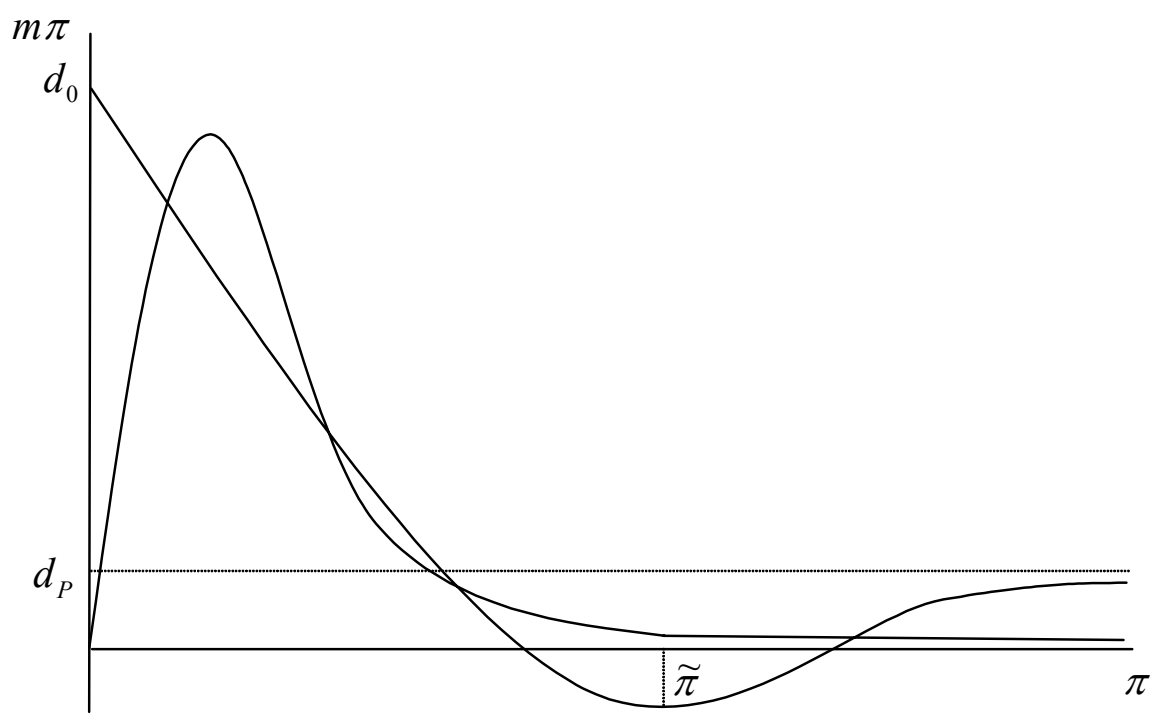

Fig. 5. Nonlinear specification of the Patinkin effect

Unfortunately, specification (7) could not be compared to specification (6) for a change in the exposed deficit $d_{E} \cdot{ }^{34}$ However, this can be done for a change in the inflation-proof deficit $d_{P}$. Numerical calculations for realistic parameter values reveal three different types of bifurcation diagrams for the change in the inflation-proof deficit $d_{P}$. Bifurcation diagrams in Fig. 6.1 (for

\footnotetext{
32 In general, the Patinkin effect operates either through the reduction of expenditures and through an increase in specific taxes (see, for example, Modigliani and Fischer, 1979, and Cardoso and Helwege, 1999). However, in the context of equation (7), this is just a matter of notation.

${ }^{33}$ Note that the specification (6) may be seen as a linear approximation of (7) for relatively small values of $u$ and $w$ and for moderate inflation. We do not study the case when the Olivera-Tanzi effect is dominant. In fact, it does not produce anything new in comparison with the linear specification of the pure Olivera-Tanzi effect that was introduced in Section 2.

${ }^{34}$ This is because the same change in $d_{E}=G-T$ may be realized by either a change in $G$ or $T$, and they may have rather different effects on the total budget deficit and the equilibrium inflation. Numerical examples for separate changes in $G$ and in $T$ produce results that closely resemble those for a change in the inflation-proof deficit.
} 
parameters $u=0.1$ and $w=0.07)$ and Fig. $6.2(u=0.2, w=0.15)$ demonstrate the coexistence of two fold bifurcations that resembles the hysteresis effect. ${ }^{35}$ The bifurcation diagram in Fig. 6.3 $(u=0.2, w=0.17)$ demonstrates a simple fold bifurcation. However, since it requires a very strong inflation feedback to the budget deficit, the hysteresis effect seems to be a more plausible outcome. The intuition behind the hysteresis can be given in the same way as for the linear specification of the Patinkin effect. This allows us to claim that the hysteresis associated with the change in the inflation-proof deficit seems to be a robust phenomenon.
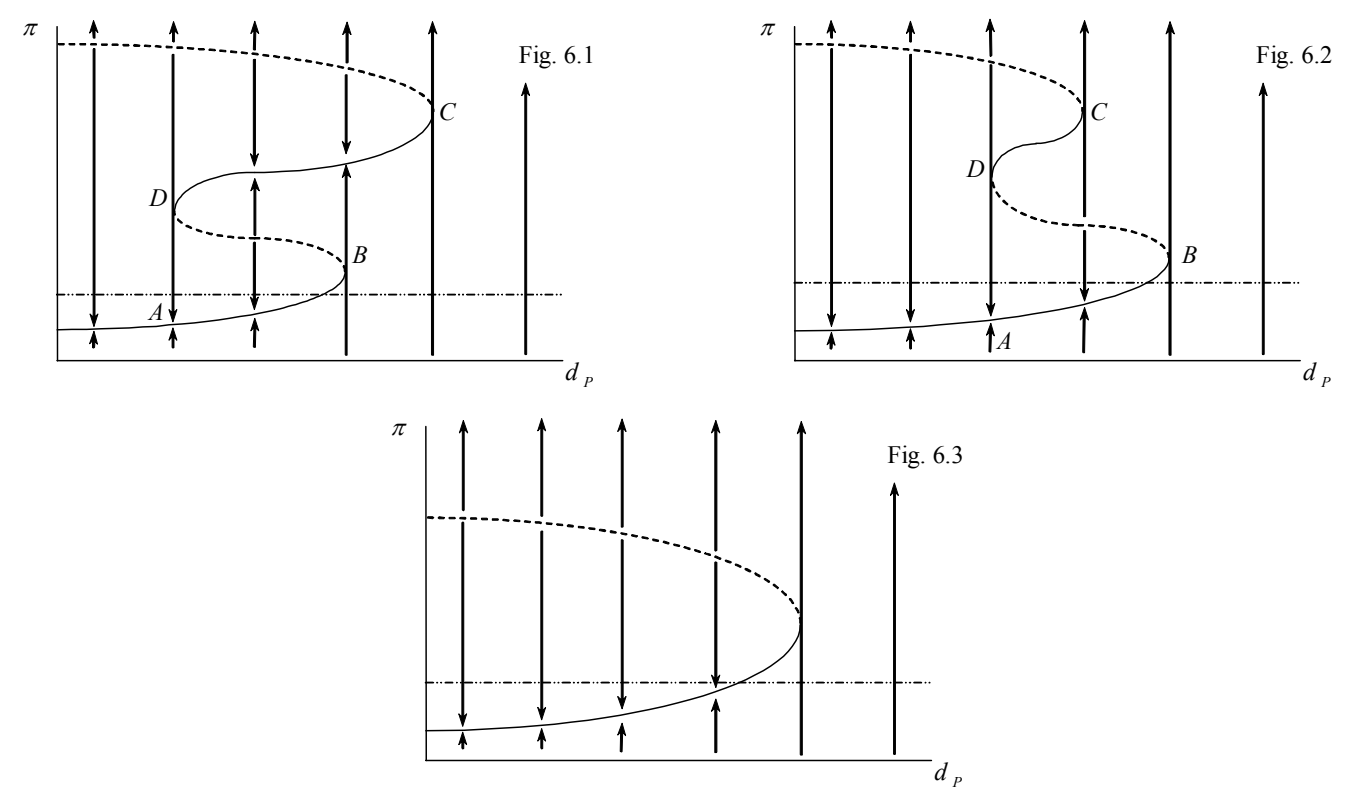

Fig. 6. Bifurcation diagrams for the change in $d_{P}$ (nonlinear specification of the Patinkin effect)

\section{Concluding remarks}

Two important problems which many developing countries face are inflation bias and deficit bias. There is reason to believe that the main source of inflation bias in developing countries is the significant financing of the budget deficit by seigniorage. This implies that inflation bias can be explained by deficit bias in many cases, especially in high inflation economies.

The stabilization of the economies in Latin America, Israel and of the transitional economies in Eastern Europe-economies with high inflation over the last decades shows that it is important to

\footnotetext{
${ }^{35}$ Fig. 6.1 represents a local hysteresis effect, as long as there is no steady state for a relatively large inflation-proof deficit (simply because point $C$ is a fold bifurcation point). The bifurcation diagram in Fig. 6.2 can be called a hysteresis with some minor reservations. The problem is that the fold bifurcation point $B$ has a lower axis than the fold bifurcation point $C$. Thus, when an increase in the inflation-proof deficit moves the economy along the branch $A B$, it eventually leads to explosive hyperinflation, not to a jump on stable branch. At the same time, a bifurcation that occurs in point $D$ leads to a jump onto the low inflation branch.
} 
not only adopt the appropriate measures, but to do so in the correct order. One of the main conclusions that one comes to after the analysis of historical cases when inflation was stabilized is that of the impossibility of stopping high inflation even in the middle run by using only monetary policies that were not first supported by stabilization in the fiscal sphere.

This paper contributes to the literature on budget deficits and inflation in high inflation economies. The main finding is that recurrent outbursts of extreme inflation in these economies can be explained by the hysteresis effect associated with public finance. This interpretation meets the evidence that dramatic shifts between regimes of moderately high and extremely high (hyper-) inflation often occur without a visible deterioration in public finance or abrupt shifts in fiscal and monetary policies. The hysteresis effect can be explicitly explained by the action of two mechanisms: the arithmetic associated with wrong side of the ITLC and the Patinkin effect. While the wrong side effect has been extensively discussed both theoretically and empirically in the literature, there is still much to be done in the empirical and theoretical research on the Patinkin effect.

Small changes in the inflation-proof part of the budget deficit (foreign or indexed debt service, among other items) and shifts in money demand (due to financial innovation, dollarization, changes in reserves requirements, etc.) are important factors that may trigger extremely high (hyper-) inflation in moderately high inflation economies. At the same time their reverse changes may act as stabilizers of hyperinflation, even if the changes are minor. This is the essence of the hysteresis effect.

Another important message of this paper is that is necessary to clearly distinguish between attempted and realized fiscal policies. As the Patinkin effect deteriorates part of the budget deficit, an attempted fiscal expansion (an increase in the exposed deficit) may actually reduce the operational budget deficit by turning the exposed deficit into a surplus at a higher inflation rate. This theoretical evidence has implications for both the discussion of inflationary consequences of budget deficits and the proper design of stabilization policy. 


\section{References}

Altinkemer M. (1994) "Financeable Deficit and Revenue from Monetization: The Case of Turkey". The Central Bank of the Republic of Turkey, Discussion Paper No. 9413.

Arce O.J. (2006) “Speculative Hyperinflations: When Can We rule Them Out?”. Banco de Espana, Documentos de Trabajo No. 0607.

Arrau P., De Gregorio J., Reinhart C.M., Wickham P. (1995) "The Demand for Money in Deeveloping Countries: Assesing the Role of Financial Innovation”. Journal of Development Economics, 46, pp. 317-340.

Bali T.G., Thurston T. (2000) "Empirical Estimates of Inflation Tax Laffer Surfaces: A 30-Country Case Study”. Journal of Development Economics, 63, pp. 529-546.

Barbosa F.H., Cuhna A.B., Sallum E.M. (2006) “Competitive Equilibrium Hyperinflation Under Rational Expectations". Economic Theory, 29, pp. 181-195.

Bental B., Eckstein Z. (1997) “On the Fit of Neoclassical Monetary Model in High Inflation: Israel 1972-1990". Journal of Money, Credit and Banking, 29(4), pp. 725-752.

Bruno M. (1989) "Econometrics and the Design of Economic Reform". Econometrica, 57(2), pp. 275-306.

Bruno M., Fisher S. (1990) "Seigniorage, Operating Rules, and the High Inflation Trap". Quarterly Journal of Economics, 105(2), pp.353-374.

Cagan, Ph. (1956) “The Monetary Dynamics Of Hyperinflation”. In Studies in the Quantity Theory of Money, ed. by M. Friedman. University of Chicago Press: Chicago.

Calvo G.A., Leiderman L. (1992) “Optimal Inflation Tax Under Precommitment: Theory and Evidence". American Economic Review, 82(1), pp. 179-194.

Cardoso E. (1998) "Virtual Deficits and the Patinkin Effect”. IMF Staff Papers, 45(4), pp. 619-46.

Cardoso E., Helwege A. (1999) "Currency Crises in the 1990s: The Case of Brazil". Unpublished paper.

Catão L.A.V., Terrones M.E. (2005) "Fiscal Deficits and Inflation". Journal of Monetary Economics, 52, pp. 529-554.

Dornbusch R. (1996) "Debt and Monetary Policy: The Policy Issues". NBER Working Paper No. 5573.

Dornbusch, R., Sturzenegger, F., Wolf, H. (1990) “Extreme Inflation: Dynamics and Stabilization”. Brookings Papers on Economic Activity, 2, pp.1-84.

Drazen A. (1985) "Tight Money and Inflation. Further Results. Journal of Monetary Economics, 15, pp. 113-120.

Drazen, A. (2000) Political Economy in Macroeconomics. Princeton University Press: Princeton. 
Drazen, A., Helpman, E. (1990) "Inflationary Consequences of Anticipated Macroeconomic Policies". Review of Economic Studies, 57, pp.147-166.

Easterly W.R., Mauro P., Schmidt-Hebbel K. (1995) "Money Demand and Seigniorage-Maximizing Inflation”. Journal of Money, Credit and Banking, 27(2), pp. 583-603.

Eckstein Z., Leiderman L. (1992) "Seigniorage and Welfare Cost of Inflation: Evidence from an Intertemporal Model of Money and Consumption”. Journal of Monetary Economics, 29, pp. 389-410.

Edwards S., Tabellini G. (1991) "Explaining Fiscal Policies and Inflation in Developing Countries". Journal of International Money and Finance, 10(Supplement 1), pp. S16-S48.

Engsted T. (1993) “Cointegration and Cagan's Model of Hyperinflation under Rational Expectations". Journal of Money, Credit and Banking, 25(3), pp. 350-360.

Engsted T. (1994) “The Classical European Hyperinflations Revisited: Testing the Cagan Model Using a Cointegrated VAR Approach”. Economica, 61(243), pp. 331-343.

Engsted T. (2003) “Misspecification versus Bubbles in Hyperinflation Data: Comment”. Journal of International Money and Finance, 22, pp. 441-451.

Evans G.W., Honkapohja S., Marimon R. (2001) "Convergence in Monetary Models with Heterogeneous Learning Rules". Macroeconomic Dynamics, 5, pp. 1-31.

Evans J.L., Yarrow G.K. (1981) "Some Implications of Alternative Expectations Hypotheses in the Monetary Analysis of Hyperinflations”. Oxford Economic Papers, 33(1), pp. 61-80.

Fischer S. (1995) “Modern Approaches to Central Banking”. NBER Working Paper No. 5064.

Fischer S., Modigliani F. (1979) "Towards an Understanding of the Real Effects and Costs of Inflation". Weltwirtschaftliches Archiv Bd. CXIV, pp. 810-833.

Fischer S., Sahay R., Vegh C.A. (2002) “Modern Hyper- and High Inflations”. Journal of Economic Literature, 40(3), pp. 837-80.

Gavrilenkov E. (1995) "Macroeconomic Stabilization and "Black Holes" in the Russian Economy". Hitotsubashi Journal of Economics, 36, pp. 181-188.

Gutierrez M.-J., Vazquez J. (2004) "Explosive Hyperinflation, Inflation Tax Laffer Curve and Modeling the Use of Money". Journal of Institutional and Theoretical Economics, 160(2), pp. 311-326.

Heymann D., Sanguinetti P. (1994) "Fiscal Inconsistencies and High Inflation". Journal of Development Economics, 43, pp. 85-104.

Imrohoroglu, S. (1993) “Testing for Sunspot Equilibria in the German Hyperinflation”. Journal of Economic Dynamics and Control, 17, pp. 289-317.

Kiguel M.A. (1989) “Budget Deficits, Stability, and the Monetary Dynamics of Hyperinflation”. Journal of Money, Credit and Banking, 21(2), pp. 148-157. 
Kiguel M.A., Neumeyer P.A. (1995) “Seigniorage and Inflation: The Case of Argentina”. Journal of Money, Credit and Banking, 27(3), pp. 672-682.

Marcet A., Nicolini J.P. (2003) "Recurrent Hyperinflations and Learning". American Economic Review, 93(5), pp.1476-1498.

Marcet A., Nicolini J.P. (2005) "Money and Prices in Models of Bounded Rationality in HighInflation Economies". Review of Economic Dynamics, 8, pp. 452-479.

Marcet A., Sargent T.J. (1989) "Least Squares Learning and the Dynamics of Hyperinflation" in W. Barnett, J. Geweke, and K. Shell, eds., International Symposia on Economic Theory and Econometrics. Cambridge University Press: Cambridge, pp. 119-137.

Marimon R., Sunder S. (1993) "Indeterminacy of Equilibria in a Hyperinflationary World: Experimental Evidence”. Econometrica, 61(5), pp. 1073-1107.

Marimon R., Sunder S. (1994) "Expectations and Learning Under Alternative Monetary Regimes: Experimental Approach". Economic Theory, 4, pp. 131-162.

Michael P., Nobay A.R., Peel D.A. (1994) “The German Hyperinflation and the Demand for Money Revisited”. International Economic Review, 35(1), pp. 1-22.

Mladenović Z., Petrović P. (2006) “Cagan’s Paradox, Seigniorage Collection and Forward-looking Behavior: Exploring Daily Data from the Extreme Portion of the Serbian Hyperinflation", unpublished manuscript.

Olivera J.H.G. (1967) "Money, Prices, and Fiscal Lags: A Note on the Dynamics of Inflation." Banca Nazionale del Lavoro Quarterly Review, 20, pp. 258-67.

Tanzi V. (1977) "Inflation, Lags in Collection and the Real Value of Tax Revenue". IMF Staff Papers, 24, pp. 154-67.

Patinkin D. (1993) “Israel's Stabilization Program of 1985, Or Some Simple Truths of Monetary Theory”. Journal of Economic Perspectives, 7(2), pp. 103-28.

Petrović P., Mladenović Z. (2000) "Money Demand and Exchange Rate Determination under Hyperinflation: Conceptual Issues and Evidence from Yugoslavia”. Journal of Money, Credit and Banking, 32(4), pp. 785-806.

Rodriguez-Arana A. (2007) "Inflation and Public Deficit When the Utility of Money is Insatiable". Japanese Economic Review, 58(2), pp. 238-254.

Sargent T.J. (1982) “The Ends of Four Big Inflations" in R.E. Hall ed. Inflation: Causes and Effects. University of Chicago Press: Chicago.

Sargent T. J. (1993) Bounded Rationalality in Macroeconomics. Clarendon Press: Oxford.

Sargent T.J., Wallace N. (1973a) "Rational Expectations and the Dynamics of Hyperinflation". International Economic Review, 14(2), pp. 328-350. 
Sargent T.J., Wallace N. (1973b) «The Stability of Models of Money and Growth with Perfect Foresight». Econometrica, 41(6), pp. 1043-48.

Sargent T.J., Wallace N. (1987) "Inflation and the Government Budget Constraint", in A. Razin and E. Sadka eds. Economic Policy in Theory and Practice. St. Martin's Press: New York, pp. 170200.

Sargent T.J., Williams N., Zha T. (2005) "Fiscal Determination of Hyperinflation”. Unpublished manuscript.

Zarazaga C.E. (1995) "Hyperinflations and Moral Hazard in the Appropriation of Seigniorage: An Empirical Implementation with a Calibration Approach”. Federal Reserve Bank of Dallas, Working Paper No. 95-17. 